\title{
LEVEL OF KNOWLEDGE AND PRACTICE OF EXTENTED PROGRAM OF IMMUNIZATION AMONG MEDICAL STUDENTS
}

\author{
Aneela Ambreen ${ }^{1}$, Rifayatullah ${ }^{1}$, Amina Zehra Iqbal', Mohammad Shadman², Shams Suleman ${ }^{3}$ \\ 1. Naseer Teaching Hospital Peshawar \\ 2. Hayatabad Medical Complex, Peshawar \\ 3. Khyber Girls Medical College
}

\section{ABSTRACT}

Objectives:

To determine the level of knowledge\& practice regarding extended program of immunization (EPI) in Pakistan among medical students.

Design:

A questionnaire based survey done amongst the students of a medical college of Peshawar.

\section{Methodology:}

A questionnaire was developed in the line with study objectives and circulated among students of third, fourth and final year of a medical college of Peshawar. Fifty students were selected from each class randomly. They were provided the assurance regarding the confidentiality of their response.

\section{Results:}

Total of 150 students was interviewed .All students were in age group 20-25 yrs. Males were $42.6 \%$ and female were $57.4 \%$. Good knowledge was observed in $27.3 \%$ of students, average knowledge was observed in $56.6 \%$ while $16 \%$ had poor level of knowledge. Regarding practice $78 \%$ used to recommend immunization to other while $22 \%$ did not give any advice regarding immunization to anyone. Most of the students having good knowledge were from final year class (16\%).

\section{Conclusion:}

Efforts towards ensuring adequate exposure to immunization education during training years are need to eliminate one of the barriers to adequate immunization in children.

Key words:

Extended Program of Immunization, Immunization, Medical Students.

\section{INTRODUCTION}

Immunization is one of the most cost effective health interventions of 20th century.EPI began in Pakistan in 1976 on pilot scale by WHO and UNICEF ${ }^{1}$ and was expanded countrywide by 1978. Initially started with six antigens, the program added two new antigens, hepatitis B in 2002 and Hib meningitis and pneumonia in $2008{ }^{2}$. The goal of this program is to prevent mortality, morbidity and disability due to vaccine preventable diseases (VPDs) and to contribute the

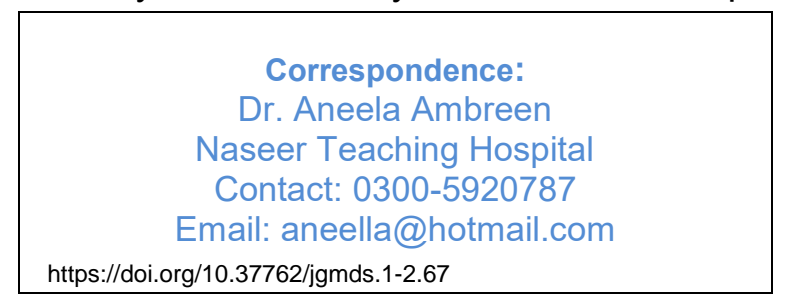
strengthening of national health system. EPI Pakistan provides vaccination against diseases to children through routine immunization (RI) and supplemental immunization activities (SIAs) against polio, measles and tetanus. The target groups are children up to 1 year age for routine immunization, 5 years for polio eradication, 9 months to 13 years for measles elimination and child bearing women for tetanus. It annually target around 5.8 million children below $1 \mathrm{yr}$ and 5.9 million pregnant women. EPI is the most exclusive provider of immunization service in Pakistan; whereas private sector provides only $3 \%$ of immunization ${ }^{4}$. 
It delivers immunization services through fixed centers and outreach and mobile vaccinations sessions annually. Immunization coverage in Pakistan needs improvement .The estimated coverage for fully vaccinated children is $56 \%$ to $88 \%$ in Pakistan with variations between different provinces $^{5}$. The reasons for inadequate immunization are several. The issue of vaccine Procurement, its storage, transport and administration are already known to contribute to inefficiency of immunization program. Carelessness on either parents or physician part, attitude of the physician, lack of identification of target age groups, social problems, lack of parents' knowledge about immunization, maternal illiteracy, vaccine cost, low socioeconomic status and refusal due to child sickness are other contributing factors to low immunization coverage ${ }^{6}$. Research has indicated that despite being the most trusted source of health information, medical students, resident and other health related professionals lack accurate and current knowledge regarding immunization practice. Health care personnel should be familiar with the most recent immunization recommendations ${ }^{7}$. Keeping all this background it was decided to conduct a pilot study amongst medical students to know their awareness regarding immunization. The ultimate goal would be to improve immunization coverage through education of our communities in area found deficient.

\section{METHODOLOGY}

This was a descriptive cross-sectional study .It was conducted among students of a medical college during the month of January 2013 .One fifty students were selected randomly from third ,fourth and final year. They were provided questionnaire to answer. The students were provided the assurance regarding the confidentiality of their response The questionnaire consisted of 10 questions for knowledge ,one question for practice .knowledge was labeled as good(>8 correct answers), average (4-7 correct answers)and bad(<3correct answer). Practice was labeled as recommending immunization to others and not recommended.

Exclusion Criteria: Students who have attended any workshop on immunization were not included for the interview. Data was collected and analyzed.

\section{RESULTS}

A total of 150 students were interviewed .fifty students were selected randomly from third, fourth and final year.

Table-1. Age \& Gender Wise Distribution of Study

\begin{tabular}{|l|c|c|}
\hline Age & $20-25$ & $150(100 \%)$ \\
\hline Gender & Male & Female \\
\hline Total & $66(44 \%)$ & $84(56 \%)$ \\
\hline
\end{tabular}

Table-2. Level of Knowledge among Medical Students

\begin{tabular}{|l|c|c|}
\hline Poor & 24 & $16 \%$ \\
\hline Average & 85 & $56.6 \%$ \\
\hline Good & 41 & $27.3 \%$ \\
\hline Total & 150 & $99.9 \%$ \\
\hline
\end{tabular}

Table-3. Level of Practice among Medical Students

\begin{tabular}{|l|c|c|}
\hline Recommended & 117 & $78 \%$ \\
\hline $\begin{array}{l}\text { Not } \\
\text { recommended }\end{array}$ & 33 & $22 \%$ \\
\hline Total & 150 & $100 \%$ \\
\hline
\end{tabular}


Table-4. Professional Year Wise Stratification Of Knowledge

\begin{tabular}{|l|c|c|c|c|}
\hline Year & Poor & Average & Good & Total \\
\hline Third yr & $20(13 \%)$ & $28(18.6 \%)$ & $02(1.3)$ & 50 \\
\hline Fourth yr & $04(2.6 \%)$ & $31(20.6 \%)$ & $15(10 \%)$ & 50 \\
\hline Final yr & $00(0 \%)$ & $26(17.3 \%)$ & $24(16 \%)$ & 50 \\
\hline Total & $24(15.6 \%)$ & $85(56.5 \%)$ & $41(27.3 \%)$ & 150 \\
\hline
\end{tabular}

Table-5. Professional Year Wise Stratification of Practice

\begin{tabular}{|l|c|c|c|c|}
\hline Year & Third yr & Fourth yr & Final yr & Total \\
\hline Recommended & $36(24 \%)$ & $42(28 \%)$ & $39(26 \%)$ & 117 \\
\hline $\begin{array}{l}\text { Not } \\
\text { recommended }\end{array}$ & $14(9.3 \%)$ & $08(5.3 \%)$ & $11(7.3 \%)$ & 33 \\
\hline Total & $50(33.3 \%)$ & $50(33.3 \%)$ & $50(33.3 \%)$ & 150 \\
\hline
\end{tabular}

Table-6. Genderwise Stratification of Knowledge

\begin{tabular}{|l|c|c|}
\hline Knowledge & Male & Female \\
\hline Poor & $16(10.6 \%)$ & $08(5.3)$ \\
\hline Average & $40(26.6 \%)$ & $55(36.6 \%)$ \\
\hline Good & $18(12 \%)$ & $23(15.3 \%)$ \\
\hline Total & $64(42.6 \%)$ & $86(57.3 \%)$ \\
\hline
\end{tabular}

\section{DISCUSSION}

Pakistan has highest death rates among children in the world. Death rates under five years are $87 / 1000$ live births. Target for (MDGs) 2015 is to reduce under 5 deaths to $52 / 1000$ live births. About a third of these child deaths are due to vaccine preventable diseases .Prevention programs particularly immunization are critical to reduce the morbidity and mortality caused by these communicable diseases. Immunization coverage surveys suggest that 1 in every 5 children is not immunized in Pakistan and in many rural areas 2 of 3 children are not immunized ${ }^{8}$. The results of the our study give insight into the knowledge and practice of immunization among medical students $.83 .3 \%$ students were aware of that EPI program exists in Pakistan .while $70.6 \%$ knew that this program is free of cost $.68 .6 \%$ knew that optimum temp for cold chain is $2-8$ celsisus. $78.6 \%$ failed to give the exact names of VPD which are included in EPI program. Only $53.3 \%$ student personally visited the EPI centers in any hospital. Level of knowledge rises with higher professional level in our study and likewise recommendations. In our study $94 \%$ students knew that vaccination is best way to prevent communicable disease similar to a study done amongst the students of rural dental college in India where $94 \%$ students were in believed that hepatitis B infection is preventable by vaccination. ${ }^{9}$ In our study $56.6 \%$ of students have average level of knowledge regarding immunization and $16 \%$ have poor level .While in a study conducted in UPR school of medicine the participant showed poor knowledge about indications(62\%correct answer, contraindications(46\%correct answer) and myths(71\% correct answer) about immunization. ${ }^{6}$ In Saudi Arabia more than $90 \%$ of school aged children are completely immunized and VPD has 
decreased more than $90 \%$ from the peak level. The reason for this achievement beside tight legislation and public health education include a high level of knowledge and appropriate standards of immunization practice among health care providers ${ }^{11}$. A KAP study conducted study among 100 qualified MBBS doctors practicing in Karachi showed that only $25 \%$ general practioners had adequate knowledge about pre exposure TT immunization ${ }^{12}$.According to a study done among undergraduate female medical students in Bangladesh $71 \%$ students started TT vaccination but only $11.36 \%$ completed the five doses $\left({ }^{13}\right)$.

\section{CONCLUSION}

Adequate knowledge and exposure should be given to the medical students during their years of training so that they can utilize preventive tool effectively during their forth coming years of practice.

\section{REFERENCES}

1. Siddiqi N,khan A,Nisar N.Assessment of EPI vaccine coverage peri -urban area. JPMA 2007; 57:391-5

2. Hasan Q, Bosan A.H, Bile K.M. A review of EPI progress in Pakistan towards achieving coverage targets: present situation and the way forward. EMHJ. 2010;16:317

3. Ministry of health, Pakistan. Expanded program on immunization.

4. coverage evaluation survey 2006.islamabad, ministry of health, expanded program on immunization ,2007

5. Coverage evaluation survey 2006. islamabad,ministry of health .EPI 2007

6. Qidwal W, Ali S, Ayub S. Knowledge, attitude and practice regarding immunization among family practice patients. JDUHUS. 2007; 1:15-19.

7. Tanson V, Borrero C, Pedrogo Y .Knowledge and misconceptions about Immunization among medical students, pediatric and family medical residents.Bol Asoc Med .2010;102 (1):5-8.

8. USAID. Childhood immunization in Pakistan .research and development solutions .policy briefs series No 3, feb 2012.

9. Saini R,Saini S,Sugandha RS.Knowledge and awareness of Hepatitis B infection amongst the students of rural dental college Maharashtra,india.Ann Nigerian Med, 2010; 4:18-20.

10. (10)Samiullah syed, ruksana $N$, perveen $K$. Awareness of immunization among students of nursing and medical technology. Medical channel .2010.199-201.

11. H Ibrahim ,S Shaffi Knowledge \& practice of childhood immunization among primary health care providers in Riyadh city .JF\&CM 2006;13(1)

12. Qadir M,Murad R,Mumtaz S. Frequency of tetanus toxide immunization among college /university female students of karachi .JAMC 2010;22(1).147-9.

13. Knowledge and practice about TT vaccination among undergraduate female medical students.Mymensingh Med j .2010; 19(4):520-3

\section{(c) (1) $\$(0)$}

